\title{
Atlanto-axial subluxation with cervical myelopathy operated with occipital C2 fusion: A case report
}

Rahul Kadam², Vishal Bauva², Krutarth Shah*3, Sunil Yadav²

\begin{abstract}
Atlanto-axial subluxation with cervical myelopathy is a rare condition that can occur mainly by trauma followed by Rheumatoid arthritis, Grisel syndrome, Down's syndrome and various other metabolic disorders. It is characterized by excessive movement of atlas (C1) over axis (C2) either by bony or ligamentous abnormality. Due to its laxity the spinal cord may get damaged and cause neurologic symptoms. Reduction and fixation is needed for such instability.
\end{abstract}

KEYWORDS: C1-C2 subluxation, Cervical myelopathy, Occipital C2 fusion.

Copyright: @ 2017. The Author. This is an open access article under the CC BY license (http://creativecommons.org/licenses/by/4. 0)

\section{INTRODUCTION}

Atlantoaxial subluxation (AASL) is rare and mostly follows trauma but in our case the etiology was a degenerative cause to the cranio-vertebral junction (CVJ) [1]. Biomechanics include a repeated force of translation of C1 over C2 which leads to cord edema which gradually leads to cervical myelopathy. Most of the patients are neurologically intact $[1,2]$. Closed reduction and collar immobilization has been reported to be successful in a few cases though intact transverse axial ligament (TAL) is a prerequisite for conservative management $[1,3]$. Most of the previously reported cases have been managed with C1-C2 fusion [1]. We describe a patient with isolated ligamentous injury, without any fractures at CVJ and with neuro deficit managed with occipital cervical fusion. It is a rare case as most of the subluxation are a cause of trauma, Grisel syndrome or RA but this is a case of chronic degeneration of the transverse ligament leading to subluxation eventually leading to myelopathy of cervical spine.

\section{TYPES OF SUBLUXATION}

\begin{tabular}{|c|c|}
\hline $\begin{array}{l}\text { Type } \\
1\end{array}$ & $\begin{array}{l}\text { - Unilateral facet subluxation with intact transverse ligament. } \\
\text { - } \quad \text { Odontoid acts as a pivot point and there is no anterior subluxation. } \\
\text { - } \quad \text { Most common and benign type. }\end{array}$ \\
\hline $\begin{array}{l}\text { Type } \\
\text { II }\end{array}$ & $\begin{array}{ll} & \text { Unilateral facet subluxation with } 3 \text { to } 5 \mathrm{~mm} \text { of anterior displacement. } \\
\text { - } & \text { Injured Transverse ligament } \\
\text { - } & \text { One facet acts as pivot point and one lateral mass is displaced }\end{array}$ \\
\hline \begin{tabular}{l|l} 
Type \\
III
\end{tabular} & $\begin{array}{l}\text { - } \quad \text { Bilateral anterior facet displacement of }>5 \mathrm{~mm} \text {. } \\
\text { - } \quad \text { Rare with higher risk of neurologic involvement or instantaneous death. } \\
\text { - } \quad \text { Both lateral masses are displaced }\end{array}$ \\
\hline $\begin{array}{l}\text { Type } \\
\text { IV }\end{array}$ & $\begin{array}{l}\text { - } \quad \text { Posterior displacement of atlas }(\mathrm{C} 1) \text {. } \\
\text { - } \quad \text { Rare with higher risk of neurologic involvement or instantaneous death }\end{array}$ \\
\hline
\end{tabular}

The present report describes a case of type II subluxation with neurological involvement. 
Table 2. Nurick Classification: Cervical spondylotic myelopathy [5]

\begin{tabular}{|c|c|}
\hline Grade 0 & - $\quad$ Signs or symptoms of root involvement without spinal cord disease \\
\hline Grade I & - $\quad$ Signs of spinal cord disease without difficulty in walking \\
\hline Grade II & - Difficulty in walking without effect on employment \\
\hline Grade III & - $\quad$ Difficulty in walking with effect on full-time employment \\
\hline Grade IV & - $\quad$ Can walk only with aid or walker \\
\hline Grade V & - $\quad$ Chair-bound or bed-ridden \\
\hline
\end{tabular}

\section{CASE REPORT}

This 55-year-old gentleman was apparently all right 4 years back when he gradually developed difficulty in walking and imbalance. There was no history of trauma. No history of Koch's, joint pain or any other metabolic disorders. His neurological examination was suggestive of he having decreased power in the upper limb with right shoulder grade 4, right elbow grade 3, right wrist grade 2 while the right lower limb power was 4 compare to the power of left upper and lower side which was grade 5. Grip was poor in the right hand. Hoffmann's sign was positive in bilateral upper limbs. Bilateral Babinski sign was positive, All deep tendon reflexes were brisk; muscle tone was increased with clasp-knife spasticity present in all four limbs. Ankle and patellar clonus was present bilaterally.

His X-ray cervical spine showed C1-C2 subluxation in flexion and extension views. Magnetic resonance imaging (MRI) of CVJ. Showed Mild subluxation of atlantoaxial joint $(3.1 \mathrm{~mm})$ with posterior displacement of dens causing narrowing of bony cervical spinal canal with reduced distance between posterior aspect of dens of $\mathrm{C} 2$ and anterior aspect of posterior arch of $\mathrm{C} 1$ vertebrae. Posterior displacement of dens is seen causing compression of cervical spinal cord at the level of C1 - C2 with significant cord focal oedema (figure 1).
Atlas is slightly displaced anteriorly in relation to baso-occiput. RA factor was negative. ESR was 18 $\mathrm{mm}$ at end of one hour and $\mathrm{C}$ reactive protein was negative.

We managed this patient with occipital cervical fusion after reduction from a posterior approach using screws and rods construct and fusion with bone graft from iliac crest. Postoperative immobilization consisted of using a hard cervical collar for 6 weeks. Post operatively the patient was able to walk without any support and tone of the muscles in lower limb decreased, no tingling or numbness are present, no signs of local infection or inflammation. Nurick grade of the patient improved from grade IV to grade I \{Figure 2).

\section{DISCUSSION}

Usually the cause of subluxation of $\mathrm{C} 1-\mathrm{C} 2$ is traumatic if not then RA but our case was of idiopathic etiology. Most of the cases with neurological deficit is associated with odontoid fracture while our case was rare with no association of any fracture. Most would agree that nonoperative treatment has little, if any, role in the definitive treatment of occipital cervical dislocations or dissociations [6]. 
Halo vest immobilization is most often used as a temporary means of stabilizing or reducing injuries until surgery can be safely performed. Longitudinal traction is contraindicated [6]. In an anecdotal case review, one group reported successful treatment of a patient with a distractive atlantoaxial injury in a halo vest [6]. The patient was reportedly without complication at 5-year follow-up. Others have reserved non-operative treatment for select patients who are neurologically intact [7]. However, the authors did not offer a reliable method for selecting appropriate candidates.

The goals of OCF are to regain normal alignment, to ensure adequate neural tissue decompression and to achieve structural stability [8]. OC-C1-C2 joint is an Osseo ligamentous complex and extremely mobile; a component of the cervical spine. It is largely believed that flexion at OC-C1 is limited by impingement of odontoid tip and extension by the tectorial membrane. There occurs a small flexion-extension movement at C1-C2 joint (of 10.1-22.4 degrees) with transverse ligament limiting flexion and tectorial membrane along with C1-C2 articular joint limiting extension [8]. In our case we did not do decompression of the patient as the reduction was enough to release the pressure of the cord and fusion was done at occiput to $\mathrm{C} 2$ level, as the reduction achieved at c1- c2 level was unstable.
The use of posterior screw/rod instrumentation constructs were associated with a lower rate of postoperative adverse events (33.33\%) ( $p<0.0001)$, lower rates of instrumentation failure (7.89\%) ( $p<$ $0.0001)$, and improved neurological outcomes $(81.58 \%)(p<0.0001)$ when compared with posterior wiring/rod, screw/plate, and on lay in situ bone grafting techniques [9].

The surgical technique associated with the highest fusion rate was posterior wiring and rods (95.9\%) ( $p$ $=0.0484)$, which also demonstrated the shortest fusion time $(p<0.0064)$ [9]. Screw/rod techniques also had a high fusion rate, fusing in $93.02 \%$ of cases [9].

When comparing outcomes of surgical techniques depending on the disease status, inflammatory diseases had the lowest rate of instrumentation failure $(0 \%)$ and the highest rate of neurological improvement (90.91\%) following the use of screw/rod techniques [9]. Occipital cervical fusion performed for the treatment of tumors by using screw/rod techniques had the lowest fusion rate $(57.14 \%)(p=0.0089)[9]$.

Traumatic causes of occipital cervical instability had the highest percentage of pain improvement with the use of screw/plates $(100 \%$ improvement) $(p<0.0001)$ [9].

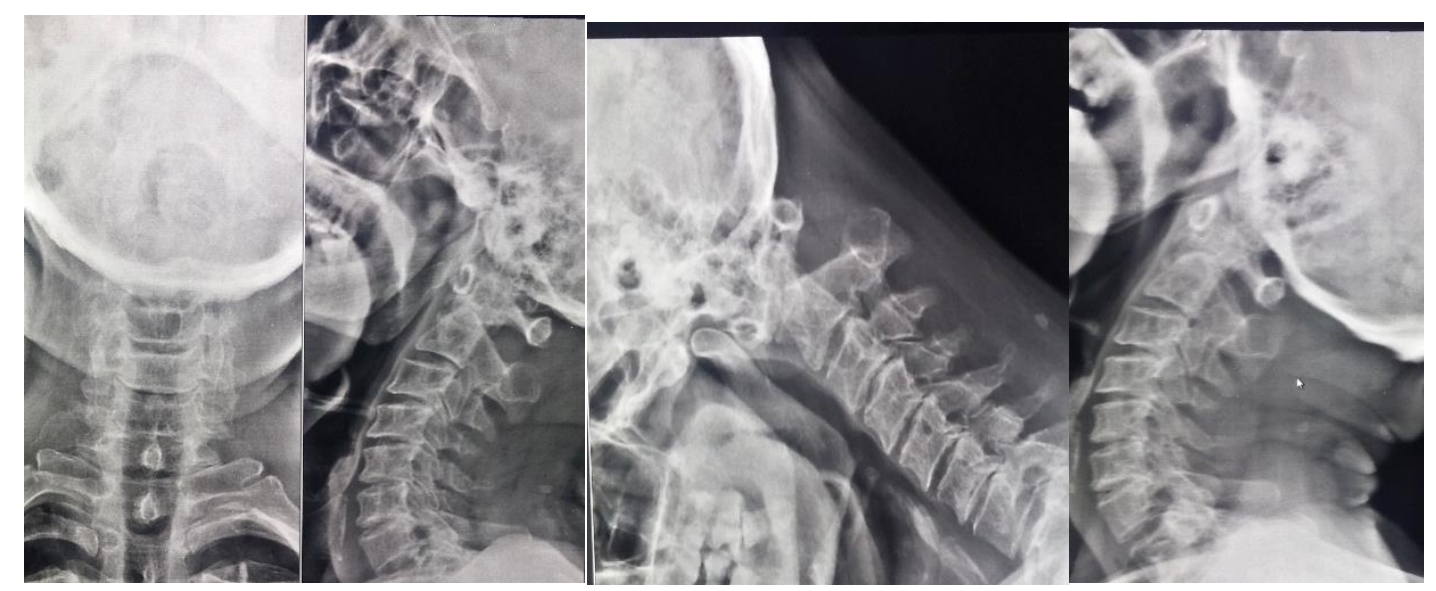

Figure 1. MRI Cervical Spine 

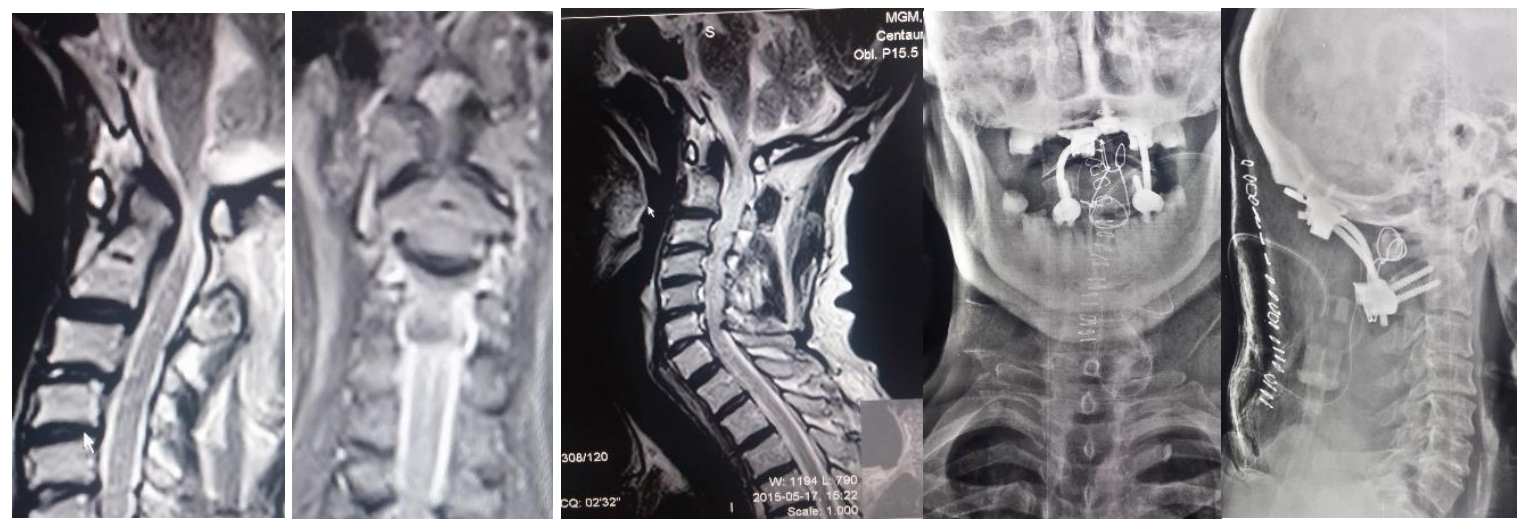

Figure 2. Post-operative X-ray of cervical open mouth AP and Lateral views

\section{References}

1. Jiang LS, Shen L, Wang W, Wu H, Dai LY. Posterior atlantoaxial dislocation without fracture and neurologic deficit: A case report and review of literature. Eur Spine J 2010:19:s118-23.

2. Zhen $\mathrm{P}$, Lan $\mathrm{X}$, Yang LW. Traumatic posterior atlantoaxial dislocation without fracture and neurological deficit. Arch Orthop Trauma Surg2011;131:681-5.

3. Chaudary R, Chaudary K, Metkar U, Rathod A, Raut A, Shangvi D. Posterior atlantoaxial dislocation without odontoid fracture. Skeletal Radiol 2008;37:361-6.

4. The Neurosurgeon's Handbook. Ed. G Samandouras. Oxford University Press, 2010

5. Williams KE, Paul R, Dewan Y. Functional outcome of corpectomy in cervical spondylotic myelopathy. Indian J Orthop. 2009 Apr.;43(2):205-209.
6. Carroll EA, Gordon B, Sweeney CA, et al. Traumatic atlantoaxial distraction injury: a case report. Spine 2001;26:454-457.

7. Huang $\mathrm{Cl}$, Chen IH, Lee LS. Traumatic atlantoaxial distractive instability: case report. J Trauma 1994;36:599-600.

8. Steinmetz MP, Mroz TE, Benzel EC. Craniovertebral junction: biomechanical consideration. Neurosurgery 2010;66:7-12

9. Winegar $C D$, Lawrence JP, Friel $B C$, Fernandez C, Hong J, Maltenfort M, Anderson PA, Vaccaro AR. A systematic review of occipital cervical fusion: techniques and outcomes. J Neurosurg Spine. $2010 \quad$ Jul;13(1):5-16. doi: 10.3171/2010.3.SPINE08143.

\section{AUTHOR'S DETAILS}

Affiliation: ${ }^{1}$ Associate Professor, Dep. of Orthopaedics, MGM Medical College, Navi Mumbai, India.

${ }^{2}$ Lecturer, Dep. of Orthopaedics, MGM Medical College, Navi Mumbai, India.

${ }^{3}$ Senior Resident, Dep. of Orthopaedics, MGM Medical College, Navi Mumbai, India.

*Corresponding Email l'd: krutarth.shah@yahoo.com

Address: Dep. of Orthopaedics, MGM Medical College \& Hospital, Navi Mumbai, India.

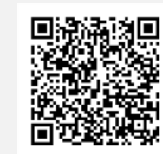

Quick Access
Date Received: $30^{\text {Th }}$ Dec, 2016

Date Accepted: $2^{\text {nd }}$ Jan, 2017

Date Published online: $3^{\text {rd } J a n, ~} 2017$

Cite this article as: Kadam R, Bahuva V, Shah K, Yadav S. (2017). Atlanto-axial subluxation with cervical myelopathy operated with occipital C2 fusion: A case report. Journal of Medical Research and Innovation, 1(1), 4-7. 